\title{
Learning from reasons given for rejected doctorates: drawing on some Swedish cases from 1984 to 2017
}

\author{
Martin Stigmar ${ }^{1}$ (iD \\ Published online: 26 October 2018 \\ (C) The Author(s) 2018
}

\begin{abstract}
The purpose of this study is twofold: (1) to survey whether dissertations have been rejected in connection with the examining committees' sessions and, if so, upon which grounds, and (2) to conduct a problematizing discussion about the pros and cons of written criteria for doctoral dissertations. In Survey One (1984-2003), responses came from the humanities, law, and social sciences in six established universities. In Survey Two (2004-2017), responses came from the same disciplines at ten universities. The surveys are based on searches in electronic databases and written responses from the faculty offices. The results show 18 cases of rejected dissertations. Five of the dissertations are written in law and five in arts, theater, culture, and film studies. Three areas appear to be particularly critical for the rejection: akribeia (accuracy and precision), methodological issues, and results and analysis.
\end{abstract}

Keywords Akribeia $\cdot$ Methodology $\cdot$ Rejected dissertations $\cdot$ Results and analysis

\section{Background and introduction to the Swedish doctoral education}

This paper explores whether examining committees in Sweden ever reject doctoral dissertations and, if so, on what grounds. A secondary question we also explore is whether it would be possible and useful to have some written criteria as quality guidelines for a doctorate.

When the public examination of the dissertation is over and the examining committee retires to assess a dissertation, the question of whether the grade setting is merely a play to the gallery often arises. Is everything predetermined or does it actually happen that dissertations are rejected? The answers given in response to this question are often based more on hearsay

Martin Stigmar

martin.stigmar@mau.se

1 Department of School Development and Leadership, Malmo University, Nordenskiöldsgatan 10, Orkanen, SE-205 06 Malmo, Sweden 
than fact. According to Wellington (2010), there has been little research on the preconceptions of doctoral students about the final examination.

Instead of accepting the uncertainty around the examining committee sessions, we decided ${ }^{1}$ to investigate whether it has occurred that dissertations have been rejected. The scientific value of the investigation is to understand the case of rejected dissertations, to determine the missteps so that doctoral students and supervisors can learn from them, and to discuss how they can be avoided in the future. It is important to point out that the phenomenon of rejected dissertations is by no means only a problem for the individual - for instance, a doctoral student, a supervisor, or an opponent. Rather, it is a departmental problem and even a university problem since it affects ranking:

Global university rankings currently attract considerable attention, and it is often assumed that such rankings may cause universities to prioritize activities and outcomes that will have a positive effect in their ranking position. (Elken et al. 2016, p. 781)

The ranking systems affect universities globally, but what is the situation in Sweden? Do examination committees at Swedish universities prioritize positive outcomes? How do universities act to maintain their legitimacy (Lim 2018)? What trends can be identified over the years, and how are the findings in the presented research applicable and relevant worldwide?

Lack of clarity is problematic for doctoral students. There are no clear guidelines for supervisors or doctoral students regarding what is considered to be an approval-worthy dissertation. Doctoral programs set goals and objectives for doctoral degrees, but as Brodin et al. (2016) claim, different meanings can be added to these goals and objectives; they are open to interpretation. The objectives also describe what the doctoral student is expected to achieve after completing doctoral research studies, not how well as stated by assessment criteria. No national criteria, in form of a principle or standard by which a doctoral thesis may be judged or decided, exist in Sweden. But how is the Swedish doctoral education organized?

\section{Introduction to the Swedish doctoral education}

A doctoral $(\mathrm{PhD})$ degree is the highest academic degree in Sweden, and it is earned after 4 years of doctoral education and passing a public defense. A Degree of Doctor is awarded after the third-cycle student has completed a study program of 240 credits in a subject in which third-cycle teaching is offered. The doctoral student must also take both basic general science courses and project-specific courses, as outlined in a study plan. Each doctoral student has their unique doctoral education but strives towards the same overall learning objectives in the Higher Education Ordinance. Their thesis should at least correspond to 2 years of full-time studies and can either be a monograph or compilation.

During the last two decades, changes have been made to the Swedish third-cycle programs - specifically, the introduction of central, national, and systematic evaluations of program subjects. Further changes include individual study plans (1998), a mandatory supervisor

\footnotetext{
${ }^{1}$ Survey One (1984-2003) was carried out by Sandstedt and Stigmar and was published in Didaktisk Tidskrift (2007). Since the editor and publisher of Didaktisk Tidskrift had not submitted the manuscript for a peer review/ collegial review, the manuscript was considered unpublished when the journal was discontinued. This article is a revised and expanded version which includes a supplementation with Survey Two (2004-2017) conducted by Stigmar 2018.
} 
education (2007), and a new degree structure along with new goals in the degree program. These reforms, in combination with local initiatives at interim seminars and final seminars (Brodin et al. 2016), mean that the quality review and the approval are progressive and formative (Sandstedt and Stigmar 2007).

Accordingly, completing a doctoral education means devoting oneself to a research project under the supervision of an experienced researcher and following an individual study plan. The individual study plan is followed-up and revised annually. The doctoral manuscript is continuously and formatively evaluated by senior researchers and other doctoral students, for instance, when a thesis chapter is presented in a seminar or at a conference (Brodin et al. 2016). Consequently, internal university committees play a domineering role in the formative assessment of doctoral students' manuscripts. However, disciplines have different traditions and culture when it comes to evaluating and improving the quality of thesis manuscripts.

The thesis is either passed or failed by the examining committee. The examining committee normally consists of three senior researchers and at least one member must be external (i.e., employed at a different university than the doctoral student). In Sweden, the public defense is final, and the doctoral student is not allowed to revise the thesis after the defense. It is important to note that in Sweden, it is the oral defense and the thesis that are examined in the dissertation session, not a broader competence.

\section{The field of tension between established practices and new thinking}

Doctoral students find themselves in a field of tension when writing their dissertations: on the one hand, they are meant to be responsive to the scientific community's established practices and conventions, and on the other hand, they are also expected to be innovative within their chosen field:

Dissertations are also an expression of the conventions. The author of a dissertation must show that he, or she, masters the various different conventions as specified by others, both locally and generally in the academic community. (Engwall 2003 p. 257)

In Homo Academicus (1996), Bourdieu deals with "the absurd resistance to intellectual change and innovative value of new knowledge" within the academic community (p. 124). According to Bourdieu, the doctoral work contributes to the strengthening of the dissertation's public defense-through obscure dependency and inherited authority that lead to loyal respect to supervisors. Bourdieu claims a doctoral student is exposed to risks when deviating from the canon education. The objective with the doctorate degree includes the capability to show both critical and creative ability. However, Brodin et al. (2016) emphasizes that critical thinking is favored and rewarded over the creative.

Schoug (2005) also comments on the conformism within the academic community in reference to the writing of a doctoral dissertation. In his investigations, he has found evidence that those who attempt to rebel have no chance within the academic community; orthodoxy is the compelling imperative. Writing a dissertation is therefore about participating in a normalization process. It seems imperative to organize third-cycle study programs that allow doctoral students to develop their ability to find a good balance between the old conventions and innovative original thinking-between critical thinking and creative thinking - two circumstances that are not always fully compatible. 


\section{Inventory of the problems}

From the above, and the absence of criteria for judging thesis quality in Sweden, it appears that there is room for different assessments and interpretations of what a dissertation worthy of approval is. How should those concerned, such as doctoral students and supervisors, understand and handle this seemingly unpredictable game? During a first problem review, the following questions emerged as the basis for the survey:

- Have dissertations been rejected in Sweden in connection with the public defense session? If so, in which subjects?

- How were the examining committee votes distributed?

- At which educational institutions have any rejections occurred, and with what reasons?

In Fig. 1, different parts in Swedish third-cycle programs are presented.

This article is divided into two parts. The first part includes two surveys of whether there are in fact any rejected dissertations. The second part involves a discussion of the pros and cons of prescribed assessment criteria for doctoral dissertations in order to generate an increased understanding of how doctoral student-supporting research environments can be developed. The results can be useful for those who supervise doctoral students in any country and subject.

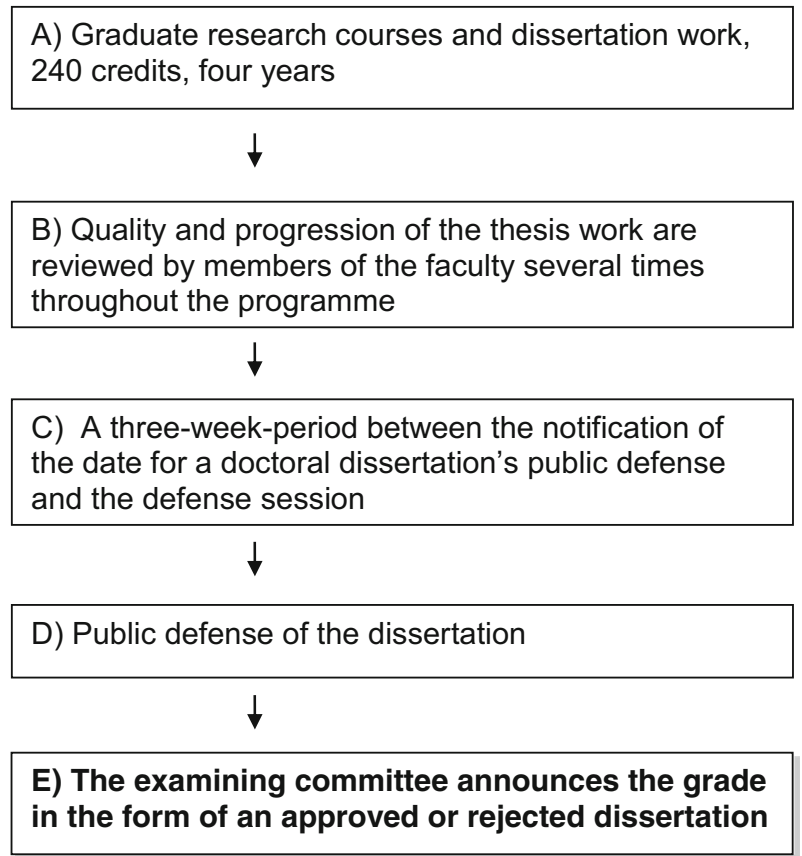

Fig. 1 The dissertation work from the start until the examining committee's statement. Survey One and Survey Two in this article focus on part " $\mathrm{D}$ " in the figure 


\section{Objective and samples}

The objective of this article is to determine whether dissertations have been rejected during the examining committees' sessions and on which grounds have the rejections occurred. Included in the purpose is to conduct a problematizing discussion about the pros and cons of written criteria for doctoral dissertations. The aim of the work is to identify critical points in the dissertation that may be essential for doctoral students to know in order to limit the risk of receiving a rejection from the examining committee. The samples came from a limited range of disciplines because of the difficulties in identifying rejected dissertations. In Survey One (1994-2003), the responses came from the humanities, law, and social sciences in six established universities. In Survey Two (2004-2017), the responses came from the same disciplines in ten universities.

The faculties of humanities, law, and social sciences were chosen because, traditionally, doctoral students in the humanities and social sciences work individually with monograph dissertations. Doctoral students in these disciplines only exceptionally participate in research teams and, therefore, do not enjoy the security and stability of compilation work. In this study, both publication forms are included - compilations and monographs. In addition, the choice of faculties was also supported by the screening results. A first screening was conducted in Biblist, a forum for news between employees and others interested in Nordic libraries. The question was raised in Biblist whether the subscribers knew of any doctoral dissertations that had been rejected at the public defense. The answers revealed that the areas within which the rejected dissertations were primarily in the humanities and social sciences.

Furthermore, Survey One was restricted to the period 1984-2003. This is motivated by the change introduced to the Swedish Higher Education Regulation in 1984:

The majority of the members shall be appointed from among teachers other than the teachers in the department to which the student belongs, unless there is a specific reason against this. At least one of them should be appointed among teachers at another faculty or at another university. (SFS 1984:705, Chapter 8, § 37)

The new regulation, stated in the quotation above, required that the examining committee members would not only be those active in their own department; rather, external members would be the majority.

The last sample restriction naturally became universities that had their own faculties in the humanities, law, and social sciences in 1984 - namely, the six established universities in Gothenburg, Linköping, Lund, Stockholm, Umeå, and Uppsala. Consequence, the number of faculty offices (which have the responsibility of filing decisions, such as the minutes of the examining committee) to contact and receive responses from was manageable. In the follow-up survey, Survey Two, four new universities (in addition to the six mentioned above) were added: Karlstad University, Linnaeus University, Mid Sweden University, and Örebro University.

In summary, the survey is not a comprehensive survey of rejected dissertations but was completed with the above-mentioned demarcations.

\section{Methodology}

Mapping out rejected dissertations proved to be challenging. The challenge lies in the absence of rules (and thus uniformity) for cataloging rejected dissertations in LIBRIS (Library 
Information System, a Swedish national union catalogue). It does not always appear that a dissertation found in LIBRIS has been rejected: there are examples of rejected dissertations that are registered in the database without such indication. Remarks like "Retracted Edition," which often means that the latter has been published in a new issue as a dissertation, or "Withdrawn diss." are ambiguous formulations. These unclear formulations imply that the dissertations may have been withdrawn before or resumed after the public defense and rejection from the examining committee. Consequently, it is difficult to search and interpret information about rejected dissertations using traditional search strategies. Documentation is not provided on literature or research that has not been published. The archives are based on the opposite; for example, Statistics Sweden (SCB) does not document rejected dissertations.

Our searches were carried out in databases to ascertain if rejected dissertations had been written about. The keywords used in different combinations were dissertation, doctoral dissertation, public defense of dissertations, public examinations of dissertations, not approved, and rejected. The results were followed up by contacting the relevant university representatives, after which the investigations were further expanded or discarded. A supplementary search was performed with the following keywords: fail, pass, withdrawn, presented, discussed, debated, and assigning the grade.

Following the initial screening survey in Biblist and the database searches described above, as well as checking for rejected dissertations according to word of mouth, the faculty offices were contacted with a request for the minutes of the examination sessions with the grade "fail." A total of 21 faculty offices at the six universities were written to, and they all responded. The results from the responses for Survey One are reported in the next section.

\section{Results of Survey One, 1984-2003}

Three of the universities - Gothenburg, Linköping, and Umeå - stated that no dissertations had been rejected at the enrolled faculties during the stated time period. However, the universities of Lund, Stockholm, and Uppsala reported 14 cases of rejected dissertations (see Table 1).

In ten of the reported cases, the examining committee had reached full agreement; on four occasions, however, disagreements had arisen. The grade range difference between 3 and 0 or $5-0$ only represents different numbers of members on the examining committee, which can differ between research subjects and is not a quality judgment. Five of the rejected dissertations were written within the field of law and three in the arts and theater and film studies. Figure 2 shows the university and year of the rejected dissertations.

The examining committees have chosen to comment on seven different occasions, and below follows a summary of the reasons given for rejection extracted from the defense session minutes.

\section{Comments of the examining committee on rejected dissertations}

In the summaries that follow, text from the minutes has been removed for being unique to the particular subject and too detailed. The texts are reproduced here as close as possible to the source. Initially, it can be noted that "The Board determines whether reasons for the decision are to be stated and if reservations are to be reported, insofar as no special regulations have been issued by the university" (Higher Education Ordinance 1998, Chapter 6, Section 34). 
Table 1 Rejected dissertations in faculties within three different disciplines (humanities, law, and social sciences) during the period 1984-2003

\begin{tabular}{lllll}
\hline Number & Year & University & Faculty & Grade \\
\hline 1 & 1984 & Stockholm University & Civil Law & $3-0$ \\
2 & 1984 & Stockholm University & Criminal and civil procedure & $5-0$ \\
3 & 1984 & Stockholm University & Economics & $5-0$ \\
4 & 1984 & Stockholm University & Political Science & $5-0$ \\
5 & 1985 & Uppsala University & Law & $3-2$ \\
6 & 1985 & Stockholm University & Public International Law & $5-0$ \\
7 & 1986 & Lund University & Civil Law & $2-1$ \\
8 & 1988 & Lund University & Sociology & $5-0$ \\
9 & 1989 & Stockholm University & Theater and Film Studies & $3-0$ \\
10 & 1991 & Uppsala University & Psychology & $3-0$ \\
11 & 1993 & Lund University & History of Religion & $2-1$ \\
12 & 1994 & Lund University & Pedagogy & $3-2$ \\
13 & 1995 & Lund University & Art History & $3-0$ \\
14 & 2003 & Lund University & Art History & $3-0$ \\
\hline
\end{tabular}

Dissertation no. 1 The limitation of the material is narrow, however acceptable. The presentation is strikingly unoriginal, and the dissertation has reproduced large parts of texts without crediting the sources. Especially the latter has led to the dissertation not being approved.

Dissertation no. 2 The dissertation has serious deficiencies in terms of methodology, material processing, argumentation technique, conceptualization, and scientific trustworthiness. The dissertation suffers from excessive deficiencies and gives an impression of being presented at a far too early stage.

Dissertation no. 3 The author has chosen an interesting and relevant topic for their dissertation. It contains a good, but incomplete, review of the literature. However, the author did not carry out his own theoretical analysis, at least not to any significant value. The author has not sufficiently considered previous research. There are deficiencies in originality and precision in the approaches that exist. We do not find that the methodological contributions have sufficient weight for the dissertation to be approved on these grounds.

Dissertation no. 5 The dissertation consists of a collection of material. Essentially, the presentation is purely descriptive. The legal cases are largely reproduced, without the author

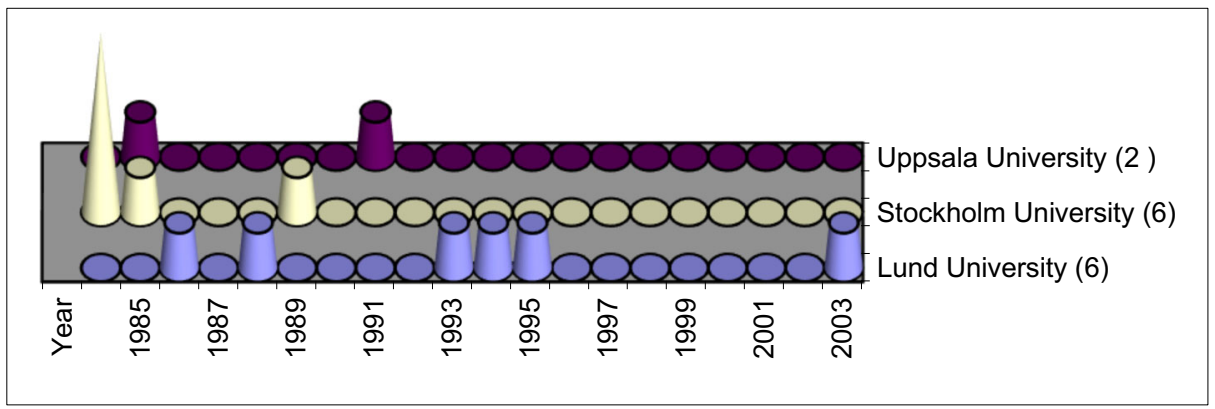

Fig. 2 Rejected dissertations in 1984-2003 from faculties within three different disciplines (humanities, law, and social sciences) 
having the capacity to distinguish between the relevant parties. The material has not been grouped according to an outline. Such a structure must undoubtedly be regarded as clearly unscientific. No overall or aggregate analysis of the various constituent elements was done, but rather the same questions return in different contexts without the author being able to take a comprehensive overall approach. No real analysis is present. The primary objection to the dissertation is that its core element and central contribution does not fulfill the minimum requirements.

Dissertation no. 6 The subject and outline of the questions are insufficiently defined. Furthermore, the technique in presentation and the choice of materials are unsatisfactory. In several places, the statements are vague and imprecise, unclear, and sometimes directly incorrect. It often does not appear whether the statements refer to current public international law, the opinions of others, or the author's own. The distribution of the material to matters of direct relevance to the dissertation and to more peripheral areas is unsatisfactory. The result is weakly founded, and the summary is incomplete in relation to the previous survey.

Dissertation no. 9 The dissertation gives an intellectually weak impression and lacks a scientific analysis. Neither footnotes nor source lists are formed in a scientific manner. Instead of following any accepted format, the author has formatted his own way of referring and making bibliographies and source listings, which are not always consistent. That the author shows an "uncritical approach to interviews and other source material is unfortunately more rule than exception." The dissertation has the character of a collection of clippings, which is clear from the abundant quotations. The relationship between quotes and the author's own text is $58 \%$ cited text and $42 \%$ interconnected/linking text. The most serious shortcoming in the dissertation lies in the absence of an implemented methodology. The dissertation is a thematic review of texts. But chronology is difficult to grasp through constant time shifts, which are not explained. As a result of the absence of a thesis or hypothesis, the argumentation that distinguishes the dissertation becomes purely additive. There is no adherence to thematic analysis in the dissertation. The author distances themselves from standard specialist and professional terminology and accepted scientific practice.

Dissertation no. 13 The author has not addressed the methodological issues systematically. The thesis lacks rigor and clarity, as well as objective and clear results. A discussion of the problems surrounding the relevant issues is non-existent. The selection of materials is not discussed, nor were reasons given for the selection. As far as literary material is concerned, this is largely misjudged and/or misinterpreted. Footnotes and bibliography are inadequate. The defense was not adequate and left the opponent's questions largely unanswered.

\section{Summary of the examining committee's comments in survey one}

The following concepts are used to clarify the deficiencies in quality in the rejected dissertations: deficient, lacking grounds and reasoning, unclear, unoriginal, insufficient, and lacking value. Three main areas appear to be particularly critical in terms of the grounds for the rejection:

1. Akribeia (accuracy and precision): deficiencies in argumentation/presentation, quotes/ footnotes, literature selection, source criticism, and scientific trustworthiness. 
2. Methodology: uncertainties around limitations, conceptualization, grounds for material choices, discussion of methodology, and establishment of goals and objections.

3. Results/analysis: insufficient results, incomplete analysis, lack of a separate theoretical analysis, a weakly founded result, an unoriginal presentation.

It is of particular interest in doctoral supervision to draw attention to the three areas listed above.

In conclusion, 14 rejected dissertations were found in Survey One. In most cases, they lacked scientific rigor, demonstrated methodological confusion, and offered weak results. At the same time, it should be said that the number of rejected dissertations is very small in proportion to the large number of approved ones during the same period of time (for quantitative specifications, see below).

Based on Survey One, a number of new questions arose. For instance, what has happened since 2003, in the period 2004-2017? If four new universities (which received university status around the turn of the millennium) are included in a follow-up survey in addition to the established six universities, what would the results look like? In order to answer these questions, a follow-up study-Survey Two-was conducted.

\section{Survey Two, 2004-2017, method and results}

In the follow-up survey, Survey Two, ten universities were examined. Four new universities were included - namely, Karlstad University, Linnaeus University, Mid Sweden University, ${ }^{2}$ and Örebro University-in addition to the six established universities from the previous survey: Gothenburg, Linköping, Lund, Stockholm, Umeå, and Uppsala. The same disciplines were studied (humanities, law and social sciences) but within a new time period (2004-2017).

A total of 21 faculty offices were contacted via e-mail, and all responded. They were requested to respond to the following questions:

1. Has any dissertation manuscript been rejected by the examining committee at your faculty during the period 2004-2017?

2. Name of the author

3. Year of the public defense of the dissertation

4. Title

5. Subject for the studies in a third-cycle program

6. The grounds and reasoning for the rejection/enclose minutes

The results, see Fig. 3 and Table 2 below, show that four rejected dissertations have been reported back: two from Stockholm University and two from Uppsala University. Table 2 presents the disciplines and grades. At the remaining eight universities, no rejected dissertations have been identified in the period 2004-2017. It is worth noting that no rejected dissertations have been reported back from the four new universities included in Survey Two.

${ }^{2}$ Mid Sweden University was granted rights to offer third-cycle study programs in 2005 . 


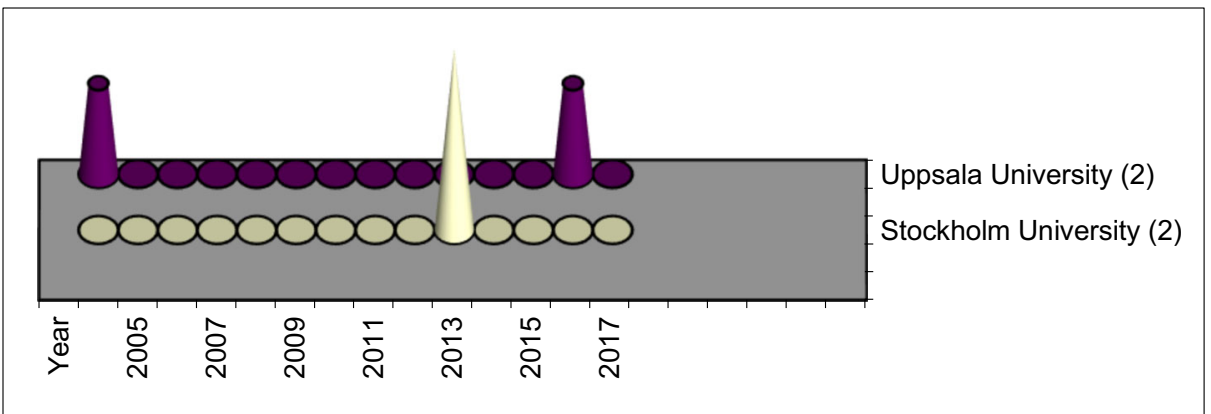

Fig. 3 Four rejected dissertations were reported during the period 2004-2017 from ten universities in Sweden. Two by Stockholm University and two by Uppsala University

\section{Comments of the examining committees}

The comments of the examining committees differ significantly with regard to extent and explanation of reasons and grounds for the rejection.

Dissertation no. 1 Large misinterpretations of the source material are made. The doctoral dissertation has the character of an unfinished work and shows deficiencies in source criticism, internal logic, and systematics. The material has been guiding the investigation, which led to lack of clear questions and a poor theoretical framework. The outline of the research has the character of a background, and in the analysis, no connection to previous research is made. The analysis also shows other insufficiencies in internal logic and scientific results.

Dissertation no. 2 The dissertation is not considered to reach an acceptable academic level. The manuscript is considered to have serious flaws in the reference system. There is no discussion about how the selection of material has been made, and the research question and overall purpose is vague. Analysis of the result is inadequately presented and discussed. The proofreading of the English text and Swedish quotes is weak.

Dissertation no. 3 The grade "fail" is based on that the scientific treatment of the subject was insufficient and at a level far below what is required for a doctorate. The public defense also had serious deficiencies. There are six problematic areas that are reported: (1) Basic theory and method. There are deficiencies in basic theory and methodology and the analysis is incomplete. (2) Knowledge of the contextual context. There is almost no scanning of the literature in the field of research; the author has not presented the relevant sources, and this has hampered the possibility to analyze and understand the material in an adequate manner. The analysis

Table 2 Rejected dissertations in disciplines in three different faculties: humanities, law and social sciences, during the period 2004-2017

\begin{tabular}{lllll}
\hline Number & Year & University & Discipline & Grade \\
\hline 1 & 2004 & Uppsala University & Ecclesiastical History & $3-0$ \\
2 & 2013 & Stockholm University & Performance Studies & $3-0$ \\
3 & 2013 & Stockholm University & Ancient Culture and Society & $3-0$ \\
4 & 2016 & Uppsala University & Human-Computer Interaction & $3-0$ \\
\hline
\end{tabular}


presented lacks depth and is presented to a large extent without interpretation. (3) The selection of study material. The reasons for the selection are not clearly stated and remain unclear. (4) The artistic context. A proper definition of the field of research is lacking, and the empirical data is undefined. (5) The study material's style and provenance. An important part of the doctoral dissertation is extremely unoriginal work and consists in practice of a compilation of information. No effort has been made to track the origin of the material that is essential for understanding and analysis. (6) The oral defense of the dissertation. The answers lacked depth, and there was no understanding for what the comments and criticisms were based on.

Dissertation no. 4 The grounds and reasoning for failing/rejection are not found in the minutes of the examining committee. The minutes only show that "After discussion, the examining committee decides to assign the doctoral dissertation the grade Fail."

\section{Summary of the examining committee's comments in Survey Two}

The three particularly critical areas mentioned above in Survey One as grounds for failing/ rejection-namely, deficiencies in terms of akribeia, methodology, and results - are also highly frequent in the minutes in Survey Two. In terms of akribeia, there are deficiencies in source criticism and references as well as lack of systematics. As far as the methodology is concerned, there is no critical discussion about the selection of source materials. The results have deficiencies in the form of unsatisfactory presentation and discussion; in other words, the analysis of the results is weak. In addition to these three critical areas, the examiners mentioned vague questions and objectives. Moreover, the oral defense of the dissertation was weak.

\section{Discussion}

The examining committee assesses the quality of a dissertation, and they have quite evidently rejected dissertations. But arriving at that point is not that simple. The dissertation work is done in a formative process where different parties participate and cooperate throughout the entire third-cycle study program. The research community consists of research-subject faculties, supervisors, seminars, opponents, second readers, and examining committees; they are all involved in piloting a dissertation. Every party in this process, especially the senior researchers, has the task of ensuring that everything goes "right" until the doctoral graduate students are "granted" access to the scientific community. In this process, practice and tradition are of great importance.

The results of both surveys lead to new research issues, and it is possible to interpret the results in several different ways. On the one hand, the results can be regarded as a failure for part of the scientific community. The research process and tradition has not prevented the rejection of 18 dissertations and the suffering for those involved - not only for authors, supervisors, opponents, the examining committee members, and relatives but also the various disciplines, faculties, and universities (with worries of loss in ranking). The third-cycle study program and its tradition, which has the responsibility to ensure that the dissertations debated at the public defense are of good quality, have not lived up to their goal.

On the other hand, the fact that there are rejected dissertations can be taken as motivation for the system to work as it should. Only 18 rejected dissertations out of a total of 15,477 
submitted dissertations in Sweden in three different faculties during the period 1984-2017 equals $0.0012 \%$. Perhaps the percentage of rejected dissertations of the total should be much higher in order to maintain quality for the third-cycle programs. The results show that although doctoral students participate in third-cycle study programs, they may still produce inferior dissertations. Further, it is still possible for dissertations of inferior quality to reach all the way to the public examination, where they are rejected. The quality requirements are so high that not all dissertations pass the public scrutiny. For that reason, the examining committee has a central role in maintaining standards.

It is worth discussing that no rejected dissertations have been reported from the new universities. Also, the number of rejected dissertations reported has significantly decreased between the two surveys. There may be several reasons for this; for instance, Survey Two was conducted over a shorter period of time (14 years, 2004-2017) than Survey One, which was over the period 1984-2003 (20 years). Moreover, senior researchers at the four new universities were particularly eager to ensure that only solid manuscripts were presented to the examining committee. The more comprehensive and systematic quality system around doctoral education and dissertation writing in recent years could also have affected the outcome.

As a result, both surveys show that rejection of dissertations does occur and the three areas that emerged as particularly critical are akribeia, methodology, and the result/analysis. However, in-depth knowledge is required to further understand how supportive research environments can be organized. How can the dissertation process (part A in Fig. 1) and the assessment be made more transparent and understandable to the doctoral students? The next section discusses the pros and cons of having specific criteria for dissertations with the objective of identifying critical points in the dissertation work that may be essential for doctoral students and supervisors to know in order to limit the risk of receiving a failing grade from the examining committee.

\section{Uncertainties in data collection}

As has been pointed out earlier, it has been relatively difficult to obtain information about rejected dissertations. One reason is that the area is sensitive to those involved and information about difficulties is often toned down. Another problem is that university libraries are not automatically notified by the educational institutions that the examining committee has rejected a dissertation; consequently, the rejected dissertations lack such indication in library databases. Neither the faculties nor the educational institutions seem to systematically document rejected dissertations. In 5 cases of the 18 rejected dissertations identified, the databases do not mark them as being rejected; therefore, there might be unreported cases here.

Another difficulty associated with the research area is that the meaning of the humanities and social sciences varies between different educational institutions, and consequently, there may be unreported rejected doctorates. A similar problem is that the university's organization (regarding faculties, departments, or subjects) is neither static nor homogeneous. Therefore, reorganization and changed archiving procedures may have affected the results discussed in this article. Overall, there is a risk that a number of cases of rejected dissertations may have been overlooked. A further complication has been the lack of minutes from the grading assessment. This concerns negligence in the writing of minutes and poor copies with low readability. For instance, at one point, it had been impossible to determine the name of the supervisor. Despite these deficiencies, the minutes of the examining committee have been 
more effective than the digital systems that seem to lack uniform procedures for the cataloging of rejected dissertations.

\section{Benefits and disadvantages of written criteria for doctoral dissertations ${ }^{3}$}

How can transparency in the dissertation process and open rules on assessment support doctoral students and supervisors? Are criteria necessary? According to Elmgren and Henriksson (2010), written criteria offer conditions for consistent assessments; however, criteria lists risk becoming instrumental and controlling.

In a survey by Sandstedt and Stigmar (2007), 19 questionnaire replies from directors of studies in third-cycle study programs in English, Business Administration, History, and Pedagogy found that 16 departments lacked detailed, written criteria for the assessment of dissertations. The lack of criteria, however, does not necessarily need to be a problem; rather, several of the directors of studies emphasized, instead of criteria, the value of the continuous and formative review process of, for instance, research plans and dissertation chapters. The process is considered more important than assessment against a set of criteria at a given point in time. Thus, the responsibility of senior researchers is central - based on experience and tacit knowledge from participation in examining committees, progressively approving dissertation manuscripts.

The same study (ibid.) reveals that neither doctoral students $(N=14)$ nor supervisors $(N=$ $15)$ request criteria for doctoral dissertations. The explanations given are that common criteria risk becoming too general and thus standardized. Assessment criteria further risk becoming outdated and inhibiting innovation, originality, and creativity (see also Elmgren and Henriksson 2010). It should be noted that originality is not explicitly mentioned in the general qualifications for the third-cycle programs in Sweden. However, for the Degree of Doctor, the third-cycle student shall make a significant contribution to the formation of knowledge through his or her own research, and according to Trafford and Leshem (2009), it is the role of examiners to assess if this has been achieved (see also Kiley 2009). Innovativeness, including unconventional perspectives that will open up new opportunities for science, is expected.

All dissertations have strong and weak sides, and the dissertation work is far too complex to be captured in a context-free list of criteria. From the above, it is clear that neither directors of studies, doctoral students, nor supervisors demand lists of criteria for assessing doctoral dissertations. Because a recognized rulebook in terms of criteria is lacking, the writing process and the communication between senior researchers become increasingly important (Brodin et al. 2016; Salzer-Mörling 2003; Torstendahl 1994).

\section{Conclusions}

The following conclusions and insights are universal and essential for doctoral students and supervisors, regardless of nationality, in order to limit the risk of a dissertation manuscript being rejected by an examining committee:

- Akribeia, methodology and results are three specific areas that require particular attention

$\overline{3}$ The text on the pros and cons of criteria for doctoral dissertations is based on Sandstedt and Stigmar (2007). 
- Process assessment, progression, and quality are formatively assessed, and active participation in the scientific community enables good socialization.

- The dissertation manuscript should be evaluated in relation to the goals for doctoral degrees.

In this article, the situation around rejected dissertations in Sweden is presented. Meanwhile, international data on doctoral thesis failure conclude that "Models of organization of the assessment of the thesis and the composition of the committee differ significantly from country to country and further discussion at European level is needed" (European University Association (EUA) Publications 2007, p. 12). The European University Association (EUA) Publications (2015) develops principles and practices for international doctoral education - focusing, for example, on supervision, funding, and mobility. Previous research also offers extensive content around the supervision role (Lee 2008) and the changing nature of the doctorate (see, e.g., Park 2005; McAlpine 2006).

However, getting a "a comprehensive, general picture of what examiners do as they assess a thesis" (Golding et al. 2014) is not easy, and establishing concrete guidelines, standards, and criteria for assessing doctoral work remains a hidden and mystified process. International failure rates are still unknown, and further research in this field is needed as well as a discussion on developing internationally and mutually recognized standards for supporting and assessing a doctoral thesis. Consequently, future research needs to focus on formative assessment and not only on the summative outcome of the dissertation. Relevant research questions are, for example, what criteria and goals for doctoral degrees exist, and how are the formative support and assessment organized in order to maintain quality in doctorate theses?

Open Access This article is distributed under the terms of the Creative Commons Attribution 4.0 International License (http://creativecommons.org/licenses/by/4.0/), which permits unrestricted use, distribution, and reproduction in any medium, provided you give appropriate credit to the original author(s) and the source, provide a link to the Creative Commons license, and indicate if changes were made.

\section{References}

Bourdieu, P. (1996). Homo Academicus. Stockholm: Brutus Östlings Bokförlag.

Brodin, E., Lindén, J., Sonesson, A., \& Lindberg-Sand, Å. (2016). Forskarhandledning i teori och praktik [research supervision in theory and practice]. Lund: Studentlitteratur.

Elken, M., Hovdhaugen, E., \& Stensaker, B. (2016). Global rankings in the Nordic region: challenging the identity of research-intensive universities? Higher Education, 72(6), 781-795.

Elmgren, M. \& Henriksson, A-S. (2010). Universitetspedagogik. [Academic Teaching]. Stockholm: Norstedts.

Engwall, L. (2003). Doktorerande, disputation och därefter [writing the doctoral dissertation, defending the dissertation, And thereafter]. In L. Strannegård (Ed.), Avhandlingen [The dissertation-about being shaped as an academic scholar]. Lund: Studentlitteratur.

European University Association (EUA) Publications. (2007). Doctoral Programmes in Europe's Universities: Achievements and Challenges. Report prepared for European universities and ministers of higher education. Brussels: European University Association.

European University Association (EUA) Publications. (2015). Principles and Practices for International Doctoral Education. Report prepared for European universities and ministers of higher education. Brussels: European University Association.

Golding, C., Sharmini, S., \& Lazarovitch, A. (2014). (2014). What examiners do: what thesis students should know. Assessment \& Evaluation in Higher Education, 39(5), 563-576.

Higher Education Ordinance, (1998), https:/www.riksdagen.se/sv/dokument-lagar/dokument/svenskforfattningssamling/hogskoleforordning-1993100_sfs-1993-100. Retrieved on August 21, 2018. 
Kiley, M. (2009). Rethinking the Australian doctoral examination process. Australian Universities' Review, $51(2), 32-41$.

Lee, A. (2008). How are doctoral students supervised? Concepts of doctoral research supervision. Studies in Higher Education, 33(3), 2008.

Lim, M. A. (2018). The building of weak expertise: the work of global university rankers. Higher Education, 75(3), 415-430.

McAlpine, L. (2006). Reframing our approach to doctoral programs: an integrative framework for action and research. Higher Education Research \& Development, 25(1), 2006.

Park, C. (2005). New variant $\mathrm{PhD}$ : the changing nature of the doctorate in the UK. Journal of Higher Education Policy and Management, 27(2), 2005.

Salzer-Mörling, M. (2003). Avhandlingsmysteriet [The Mystery of the Dissertation]. In: L. Strannegård (ed.) Avhandlingen - om att formas till forskare [The dissertation - about being shaped as an academic scholar] (pp. 167-182). Lund: Studentlitteratur

Sandstedt, T., \& Stigmar, M. (2007). Om kriterier för avhandlingar-form, struktur, innehåll och socialisation [criteria for the format, structure, contents and socialization of the dissertation]. Stockholm: Liber.

Schoug, F. (2005). Föreläsningsanteckningar från forskarhandledarutbildningen i Sydost [lecture notes from the training for academic supervision of postgraduate students in the southeast, 2005-03-21].

Swedish Code of Statutes (SFS) (1984) 1984:705. (Swedish Higher Education Act and Regulation). Stockholm: Nordstedts Juridik.

Torstendahl, R. (1994). Reglerade minimikrav och opitmumnormer [regulated minimum requirements and optimum norms]. In S. Langholm, K. Lunden, T. Nordby, F. Sejersted, \& Ö. Sörensen (Eds.), Den kritiske analyse [The critical analysis.] Celebration text to Ottar dahl on his 70th birthday, January 5, 1994 (pp. $43-$ 62). Oslo: Universitetsforlaget.

Trafford, V., \& Leshem, S. (2009). Doctorateness as a threshold concept. Innovations in Education and Teaching International, 46(3), 305-316.

Wellington, J. (2010). Supporting students' preparation for the viva: their pre-conceptions and implications for practice. Teaching in Higher Education, 15(1), 71-84. 